\title{
Impactos dos Subsídios Agrícolas dos Estados Unidos na Expansão do Agronegócio Brasileiro
}

\author{
- Adelson Martins Figueiredo*

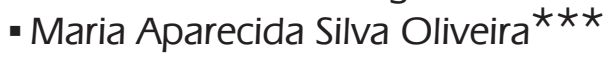

\author{
- Maurinho Luiz dos Santos*ᄎ

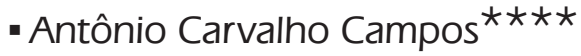

\begin{abstract}
Resumo
Nos fóruns de negociações multilaterais da Organização Mundial de Comércio subsiste veemente debate com intuito de eliminar as subvenções agrícolas nos países desenvolvidos. Contudo, os Estados Unidos têm aumentado o volume desses subsídios, causando distorções no comércio agrícola mundial. Assim, o objetivo desta pesquisa foi avaliar os impactos desses subsídios norte-americanos (Loan Deficiency Payments), concedidos no período de 2002 a 2007, sobre o crescimento do agronegócio brasileiro. Os resultados permitem inferir que a redução dos subsídios nos EUA propiciaria o crescimento da produção agroindustrial brasileira e ampliaria o superávit na balança comercial desse setor, com crescimento conjunto das exportações e importações. Portanto, cortes nesses subsídios contribuiriam para maior competitividade das exportações brasileiras e gerariam oportunidades para o crescimento do agronegócio.
\end{abstract}

\section{Palavras-Chave}

subsídios agrícolas, EUA, agronegócio, Brasil

\begin{abstract}
In the forums of multilateral negotiations of the World Trade Organization (WTO) there has been a strong debate which tries to eliminate the agricultural subventions in the developed countries. However, the United States has increased the amount of these subsidies causing distortions in the world agricultural trade. Therefore, the purpose of this research has been to evaluate these American subsidies impacts (Loan Deficiency Payments) given between 2002 and 2007 upon the Brazilian agribusiness growth. The findings allow to deduce that the reduction of the subsidies in the United States might promote the growth of the Brazilian agribusiness production and might produce trade surplus in the trade balance in this sector as well as the growth of both exports and imports. Hence the cuts in these subsidies would contribute to a bigger competitiveness of the Brazilian exports and would generate opportunities to the agribusiness growth.
\end{abstract}

\section{Keywords}

agricultural subsidies, United States, agribusiness, Brazil

\author{
JEL Classification \\ Q17, Q18, C68
}

\footnotetext{
* Universidade Federal de São Carlos, Campus Sorocaba. E-mail: adelson@ufscar.br.

** Departamento de Economia Rural, Universidade Federal de Viçosa (DER/UFV). E-mail: mlsantos@ufv.br.

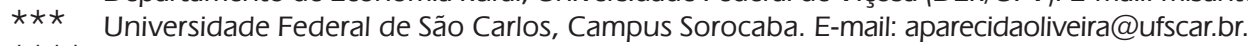

$\star \star \star \star$ Departamento de Economia Rural, Universidade Federal de Viçosa (DER/UFV). E-mail: accampos@ufv.br. Endereço para contato: Universidade Federal de São Carlos, Campus Sorocaba - Rod. João Leme dos Santos, Km 110 - SP 264 - Bairro Itinga - Sorocaba - SP. CEP: 18052-980.

(Recebido em setembro de 2008. Aceito para publicação em agosto de 2009).
} 


\section{Introdução}

Os subsídios à produção agrícola nos EUA representam pelo menos duas grandes barreiras ao crescimento do agronegócio brasileiro. Primeiramente, porque os subsídios à produção interna dos EUA contribuem para redução de suas importações de produtos agroindustriais, os quais, em grande parte, são comprados do Brasil. Em segundo lugar, os EUA são uma grande economia e, quando subsidiam a produção a ponto de gerar excedentes exportáveis, há aumento da oferta dos produtos agrícolas no mercado internacional. Assim, países exportadores agrícolas tradicionais, como o Brasil, vendem menos e, portanto, obtêm menores receitas de exportação. Destacase que países em desenvolvimento, especialmente o Brasil, que é exportador líquido de produtos de origem agrícola, têm, nessa atividade, uma fonte importante de geração e manutenção de crescimento econômico.

Apesar da assinatura do Acordo Agrícola da Rodada Uruguai (AARU), bem como da proposição de novas metas de redução de subsídios em posteriores rodadas de negociações multilaterais de comércio, os países continuaram subsidiando a agricultura de forma expressiva. Nas notificações de aplicação de subsídios pelos países desenvolvidos, verifica-se que os Estados Unidos da América (EUA) vêm aumentando o volume de subsídios da modalidade amber box ou caixa amarela. Salientase que os subsídios classificados como caixa amarela devem ser reduzidos, porque eles distorcem o comércio internacional. Fazem parte dessa modalidade as políticas de garantias de preços mínimos e os programas de pagamentos aos produtores, ou seja, quaisquer políticas que sejam capazes de distorcer preços e quantidades de mercado.

Na Figura 1, é apresentada a evolução das concessões de subsídios à produção ou Medida Agregada de Suporte (AMS) de EUA, União Europeia (UE) e Japão (JPN). A AMS é a medida do montante de apoio interno ou de subsídios domésticos conferidos ao setor agrícola. Essa medida é utilizada como parâmetro para as notificações à $\mathrm{OMC}$, sendo frequentemente usada em análises e negociações comerciais, envolvendo o setor subsidiado (JANK; JALES, 2003). Percebe-se que, embora os subsídios concedidos pelos países da UE e pelo Japão sejam elevados, o montante dessas concessões tem se reduzido significativamente ao longo do tempo. As concessões da UE caíram de cerca de US\$ 67 bilhões, em 1995, para US\$ 35 bilhões, em 2001. O Japão, por sua vez, reduziu suas concessões de forma mais significativa e rápida do que a UE. O valor das concessões japonesas diminuiu de aproximadamente US $\$ 36$ bilhões em 1995, para cerca de US\$ 6 bilhões, em 1998, estabilizandose nos anos subsequentes em torno desse mesmo patamar. Enquanto isso, os EUA têm elevado significativamente os volumes de recursos concedidos aos produtores, mesmo sendo esses recursos de uma categoria de subsídios a serem reduzidos. As 
concessões norte-americanas quase triplicaram de 1995 para 2001, passando de um valor aproximado de US\$ 7,7 bilhões, em 1995, para pouco mais de US\$ 21 bilhões em 2001.

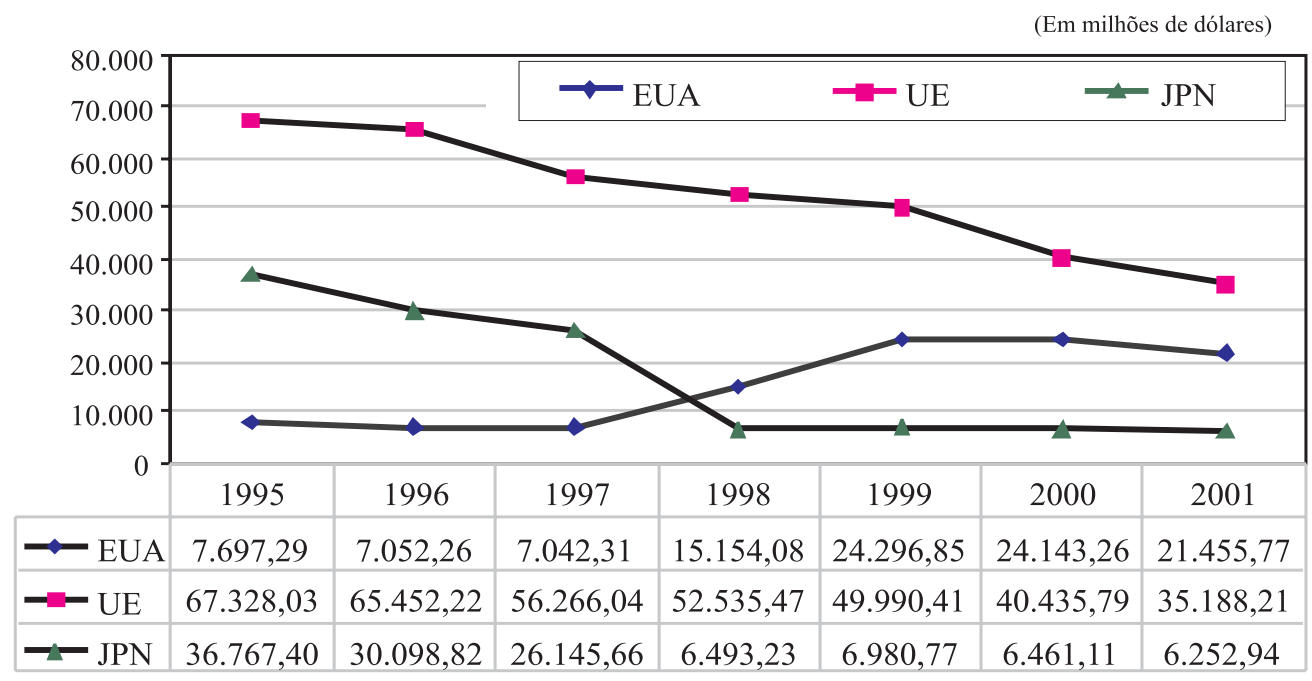

Fonte: USDA/ERS (2006). Elaborado pelo autor.

Figura 1 - Notificações de Subsídios à OMC no Período de 1995 a 2001

Com o Farm Security and Rural Investment Act (FSRIA) de 2002, houve elevação do volume de recursos destinados a apoiar a agricultura nos EUA. Conforme Beraldo (2002), os gastos médios previstos com subsídios nos EUA, para os anos compreendidos entre 2002 e 2011, são de US\$ 41 bilhões. Orden (2002) destaca que, apenas com pagamentos extras autorizados pelo Congresso, os agricultores dos EUA receberam cerca de US\$ 20 bilhões de pagamentos diretos do governo em 2002, ou seja, aproximadamente $40 \%$ da renda líquida desses agricultores advieram de recursos governamentais. Em 2004, os subsídios totais dos EUA atingiram US\$ 43,45 bilhões (BEA, 2005).

Apesar da importância dos subsídios à produção agrícola nos demais países desenvolvidos (PDs), principalmente na União Europeia (UE) e no Japão, os subsídios incidentes sobre a produção agrícola dos EUA foram uma das causas principais da não concordância do Brasil com a formação da Área de Livre Comércio das Américas (ALCA). Além disso, segundo Schuh (2004), os subsídios agrícolas dos EUA e da UE diferem substancialmente. Esta tende a usar subsídios explícitos às exportações, enquanto os EUA utilizam subsídios implícitos às exportações, na for- 
ma de pagamentos aos produtores. Destaca-se que os subsídios implícitos são mais prejudiciais, pois causam fortes distorções nos preços internos de produtos exportáveis, tornando-os mais baixos (SCHUH, 2004). Assim, ajudam o país a adquirir vantagens competitivas em relação aos seus concorrentes no mercado externo.

Portanto, nesta pesquisa, a hipótese é de que os subsídios à agricultura norteamericana geram distorções no comércio, causando empecilhos ao crescimento e desenvolvimento do agronegócio brasileiro. Assim, objetivou-se avaliar os impactos dos subsídios à produção agrícola dos EUA - concedidos através dos Loan Deficiency Payments $^{1}$ (LDP) - sobre o crescimento do agronegócio brasileiro. Especificamente, pretendeu-se determinar os impactos de reduções nesses subsídios dos EUA sobre a produção, exportação e importação das economias norte-americana e brasileira. Destaca-se que esse tipo de análise é importante devido à carência de estudos que quantifiquem os efeitos das políticas de subsídios à produção dos EUA sobre a economia brasileira.

\section{Metodologia}

Para mensurar as interações entre os agentes econômicos, é preciso modelar seus comportamentos. Essa modelagem é feita por meio dos Modelos Aplicados de Equilíbrio Geral (MAEGs) para a economia dos EUA e do Brasil, em que são usadas formulações matemáticas para cada ação de interesse dos agentes econômicos. Entretanto, apenas pela representação matemática desses modelos nem sempre é possível perceber claramente as principais características do mesmo e o sentido dos fluxos econômicos. Dessa maneira, na Figura 2, é apresentado um esquema em que, por meio da tecnologia disponível, os produtores combinam os fatores produtivos. Conforme necessidades das firmas e das famílias norte-americanas, são realizadas as importações de bens e serviços que, nesta pesquisa, foram desagregadas em importações oriundas do Brasil e do Resto do Mundo (RM). O somatório das mercadorias domésticas e importadas forma a oferta total interna ou disponibilidade doméstica. O total dos bens e serviços disponíveis pode ser ofertado no mercado interno ou no mercado externo, para o Resto do Mundo. De forma análoga, essa mesma análise pode ser feita para as atividades produtivas da economia brasileira, observando a Figura 2 da direita para a esquerda. A única diferença é que as importações brasileiras são tratadas de forma agregada. Segundo Castilho (1994), a presença do governo dá-se pelo recolhimento de impostos e taxas e pelos gastos que efetua no lado da demanda. Soma-se a isso o fato de que o governo pode afetar

1 Os LDP fazem parte das políticas de suporte de preços dos EUA, por meio das quais os produtores recebem do governo um pagamento complementar equivalente à diferença entre os preços de mercado e os preços mínimos ou Loan Rates. 
tanto a distribuição dos fatores entre as atividades econômicas como a produção e disponibilidade internas, por meio de subsídios à produção. Nesse último caso, considera-se ainda que as distorções na produção interna dos EUA, devido aos subsídios, podem, em alguns casos, gerar reações na produção e disponibilidade no Brasil, sendo essas reações maiores ou menores, dependendo das parcelas de mercado desse último país no mercado mundial. Por fim, das vendas finais dos bens e serviços aos mercados interno e externo, são gerados recursos financeiros com os quais é feita a remuneração final dos fatores produtivos.

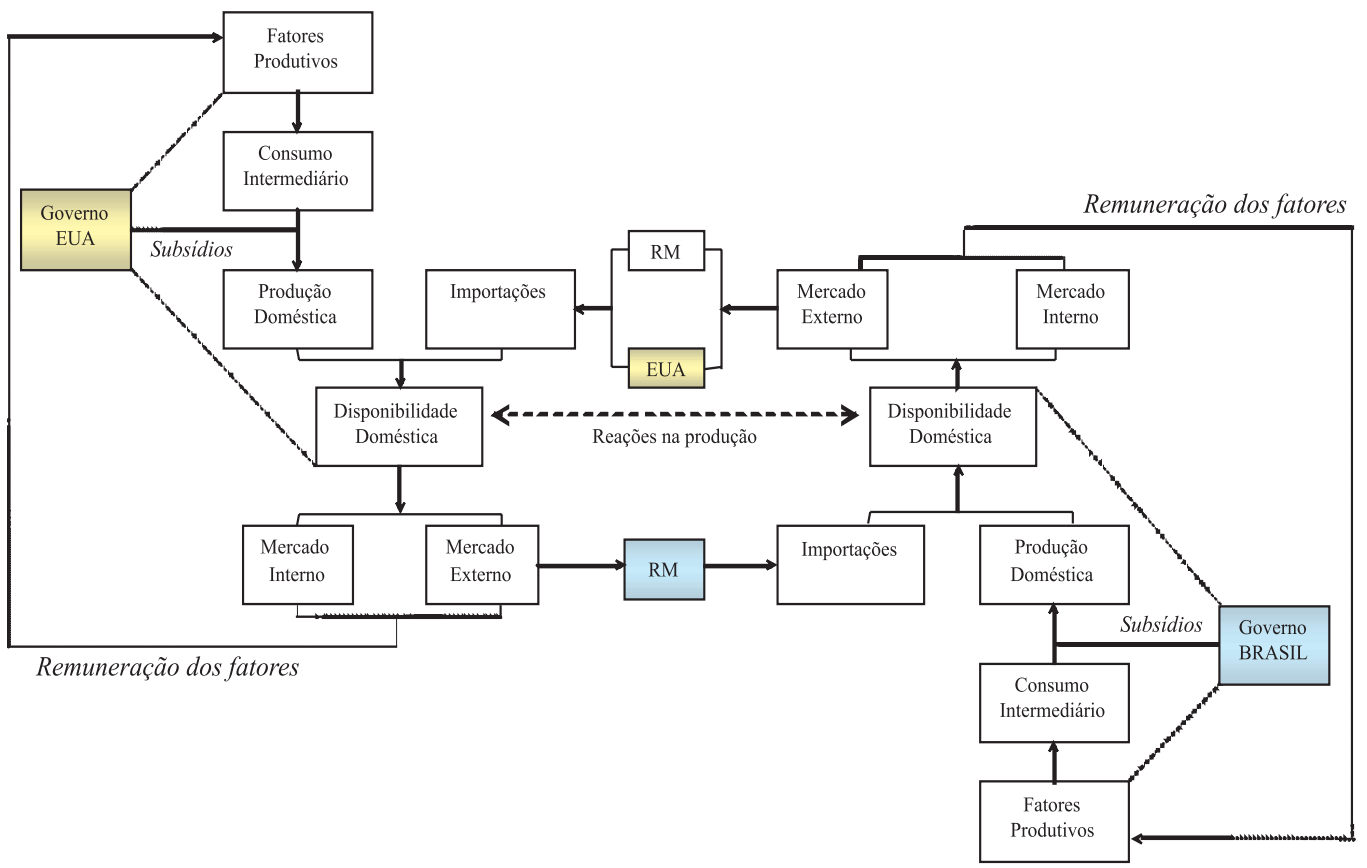

Fonte: Adaptado de Castilho (1994) e Lirio (2001).

Figura 2 - Estrutura Hipotética de um MAEG para Dois Países 
De acordo com a Figura 2, fica evidente que a concessão de subsídios pode gerar uma sucessão de efeitos capazes de afetar a produção doméstica, a necessidade de importações e, portanto, a disponibilidade doméstica de bens e serviços. Dessa forma, dependendo do efeito dos subsídios sobre a disponibilidade de bens e serviços domésticos, podem ocorrer impactos significativos na comercialização interna e externa desses bens e serviços, devido a alterações na remuneração interna dos fatores produtivos e a reações na produção de outros países. ${ }^{2}$

\subsection{Formulação do Cenário Simulado}

No processo de montagem do cenário de redução dos subsídios na agricultura norte-americana, foi selecionado o seguinte instrumento de política agrícola: Loan Deficiency Payments (LDP). A escolha desse instrumento é justificada por sua capacidade de distorção no comércio, além de o próprio United States Department of Agriculture (USDA) classificá-lo como subsídios caixa amarela (amber box), devendo, portanto, ser reduzidos.

No cenário simulado foi efetuado um corte de $60 \%$ no valor médio dos subsídios LDP concedidos pelos EUA no período 2002-2007. Esse porcentual foi estipulado tendo como base as metas estipuladas pela OMC nas negociações multilaterais de comércio da Rodada Doha, em que foi criado um sistema de bandas ${ }^{3}$ para cortes porcentuais no valor dos subsídios amber box, sendo o corte de $60 \%$ o porcentual mínimo estipulado para a banda 2, na qual se enquadravam os EUA.

Como foram simuladas políticas de redução de subsídios à produção, as variáveis alteradas no modelo de equilíbrio geral da economia norte-americana com os choques foram: $s_{i}^{X}=$ subsídios à produção e $t_{i}^{X}=$ alíquota do imposto indireto incidente sobre a produção doméstica. Quanto à economia brasileira, foram alteradas a oferta setorial doméstica, $X_{i}$, e as demandas de exportação setoriais, $E_{i}$.

Os modelos de Brasil e EUA foram interligados pelos fluxos comerciais. Para isso, usaram-se hipóteses de market-share constante, ${ }^{4}$ ou seja, as reduções de subsídios são simuladas na economia norte-americana e, sob a hipótese de que o Brasil mantenha seu market-share no mercado internacional, os choques são transmitidos para o modelo de equilíbrio geral da economia brasileira.

2 Um resumo do modelo matemático usado nesta pesquisa é apresentado no Apêndice A.

3 Para detalhes, consultar OMC (2005).

4 Apresentação detalhada deste modelo pode ser encontrada em Leamer e Stern (1970), Carvalho (1995), Stalder (1997), Burnquist e Miranda (1999) e Figueiredo (2004). 
Denominando o market-share do Brasil nas importações setoriais dos EUA de $\left(M S M_{i}^{B R A}\right)$ e o market-share do Brasil nas exportações setoriais mundiais de (MSE $E_{i}^{B R A}$ ), as variações nos fluxos da balança comercial do Brasil podem ser obtidas da multiplicação de sua parcela de mercado pelas variações nas importações dos EUA e pelas variações nas exportações mundiais, respectivamente. Dessa maneira, as variações líquidas no balanço de comércio setorial do Brasil $\left(V L B C_{i}^{B R A}\right)$ são iguais à soma das variações nas importações setoriais dos EUA, multiplicadas pela parcela de mercado do Brasil nas importações dos EUA $\left\{\left(\Delta M_{i}^{E U A}\right) \times\left(M S M_{i}^{B R A}\right)\right\}$, e das variações nas exportações mundiais, multiplicadas pela parcela de mercado do Brasil nas exportações mundiais $\left\{\left(\Delta E_{i}^{E U A}\right) \times\left(M S E_{i}^{B R A}\right)\right\}$. Na presença de apenas duas regiões, as variações nas exportações mundiais são iguais às variações nas exportações dos EUA. A partir disto pode-se escrever a seguinte equação, que permite calcular as variações no balanço de comércio setorial do Brasil decorrentes da redução dos subsídios na agricultura norte-americana:

$$
V L B C_{i}^{B R A}=\left\{\left(\Delta M_{i}^{E U A}\right) \times\left(M S M_{i}^{B R A}\right)\right\}+\left\{\left(\Delta E_{i}^{E U A}\right) \times\left(M S E_{i}^{B R A}\right)\right\}, i=1,2, \ldots, 15
$$

A inclusão das hipóteses de market-share constante e a adoção desses procedimentos são importantes, pois permitem computar as variações potenciais de longo prazo das exportações brasileiras, devido ao efeito competitividade. Outra hipótese utilizada é de que o Brasil reage às variações da produção setorial mundial, devido às variações da produção setorial nos EUA, em proporção igual ao seu marketshare no valor da produção setorial mundial. Essa hipótese pode ser considerada conservadora, pois trata as importações do Resto do Mundo de forma agregada, não permitindo mensurar as possíveis variações na produtividade das economias não desagregadas. Ademais, não incorpora o efeito competição entre essas últimas economias e Brasil e EUA.

\subsection{Fonte de dados}

Neste estudo, as matrizes insumo-produto (MIP) do Brasil e dos Estados Unidos foram utilizadas para montar as respectivas Matrizes de Contabilidade Social (MCS), usadas como base de dados dos Modelos Aplicados de Equilíbrio Geral (MAEGs). As tabelas de insumo-produto para o Brasil foram obtidas no Banco do Amazonas S/A (BASA). Essas tabelas são referentes ao ano de 1999 e foram construídas por Guilhoto e Sesso Filho (2005). Os demais dados usados na montagem da Matriz de Contabilidade Social do Brasil foram obtidos do Instituto de Pesquisa Econômica Aplicada (IPEA), do Banco Central do Brasil (BACEN) e do Instituto Brasileiro de Geografia e Estatística (IBGE). 
As tabelas de insumo-produto dos EUA, referentes também ao ano de 1999, foram disponibilizadas pelo Bureau of Economic Analysis (BEA). Os dados adicionais, utilizados para estruturação da MCS dos EUA, foram obtidos no BEA e no Federal Reserve Bank (FED). Os parâmetros de substituição entre fatores e produtos domésticos e importados, tanto para o Brasil como para os Estados Unidos, foram obtidos do Global Trade Analysis Project (GTAP) versão 6.02.

As matrizes de insumo-produto de Brasil e Estados Unidos foram estruturadas de acordo com a metodologia proposta pela Organização das Nações Unidas (ONU) em 1993,5 que integra as matrizes de insumo-produto ao sistema de contas nacionais. Na montagem dessas matrizes, usou-se a tecnologia baseada na indústria e suas apresentações finais foram elaboradas em uma estrutura de setor por setor ou de indústria por indústria.

A conversão dos valores em dólares para reais, e vice-versa, foi realizada utilizandose a média da taxa de câmbio comercial de venda - mensal em R \$/US\$ e fim de período - referente ao ano de 1999. Essa série da taxa de câmbio mensal foi obtida no IPEA; posteriormente, calculou-se a sua média anual, que foi de aproximadamente $\mathrm{R} \$ 1,85$ por dólar. O modelo da economia brasileira foi calibrado para uma taxa de desemprego de $7,56 \%$ e o da economia norte-americana considerando uma taxa de desemprego de 4,20\%. A taxa de desemprego do Brasil foi obtida no IBGE e a dos EUA, no Bureau of Labor Statistics (BLS).

Os dados referentes aos subsídios por instrumento de política agrícola dos EUA foram fornecidos pelo USDA, sendo que os valores disponibilizados são referentes ao período de 2002 a 2007. Os valores dos dois últimos anos das séries correspondem a projeções realizadas pelo próprio USDA. Os dados de subsídios utilizados na simulação feita pelo MAEG referem-se ao período de vigência do FSRIA 2002, ou seja, 2002 a 2007.

As agregações utilizadas para montagem das MCS de Brasil e EUA são apresentadas no Quadro 1. As MCS de EUA e Brasil têm dimensões idênticas, com 15 setores, mais 6 componentes da demanda final.

5 Para detalhes sobre esta metodologia, ver Ramos (1996), Feijó et al. (2003) e Guilhoto e Sesso Filho (2005). 


\begin{tabular}{|cl|}
\hline Agregações da pesquisa & \multicolumn{1}{c|}{ Setores } \\
\hline 01 & Cana-de-açúcar e beterraba \\
02 & Soja \\
03 & Milho \\
04 & Fruticultura \\
05 & Outros da agricultura \\
06 & Pecuária \\
07 & Carnes \\
08 & Indústria do açúcar e álcool \\
09 & Outros agroindustriais \\
10 & Adubos e fertilizantes \\
11 & Energia \\
12 & Madeira e mobiliário \\
13 & Outras indústrias \\
14 & Comércio \\
15 & Serviços \\
\hline
\end{tabular}

Fonte: BASA (2004) e BEA (2005). Elaborado pelo autor.

\section{Quadro 1 - Agregações das Matrizes de Insumo-Produto do Brasil e dos EUA}

A correspondência entre os setores da economia brasileira e dos EUA é garantida devido à utilização do sistema harmonizado, conforme agregações da North American Industry Classification System (NAICS).

\section{Resultados e Discussão}

O valor médio anual dos subsídios LDP concedidos na agricultura norte-americana no período de 2002 a 2007 foi de, aproximadamente, US\$2,55 bilhões. Com a redução simulada de $60 \%$ na média anual dos LDP, nos seis anos de FSRIA, foi efetuado um corte de cerca de US\$ 1,53 bilhão nesses subsídios.

\subsection{Alterações na Produção, Exportações e Importações Agroindustriais de EUA e Brasil}

A redução simulada dos LDP gerou os resultados apresentados na Tabela 1. Desses resultados, verifica-se que as mudanças na produção setorial dos EUA seriam, em geral, negativas. Destaca-se que a queda na produção do agronegócio dos EUA diminuiria os excedentes exportáveis desse país, gerando maiores oportunidades de expansão do agronegócio em países concorrentes. Esse enunciado é verificado para o Brasil, que apresentaria mudanças, em geral, positivas na produção. 
Tabela 1 - Variações Porcentuais na Produção, nas Exportações (E) e nas Importações (M) Setoriais Devido à Redução de $60 \%$ na Média Anual dos LDP dos EUA, no Período 2002-2007

\begin{tabular}{|c|c|c|c|c|c|c|}
\hline \multirow[t]{2}{*}{ Setores } & \multicolumn{2}{|c|}{ Produção } & \multicolumn{2}{|c|}{ EUA } & \multicolumn{2}{|c|}{ BRA } \\
\hline & EUA & BRA & $\mathrm{E}$ & $M$ & E & $M$ \\
\hline Cana-de-açúcar e beterraba & $-0,68$ & 0,23 & $-0,21$ & $-0,63$ & 0,05 & 0,19 \\
\hline Soja & $-5,73$ & 3,80 & $-2,82$ & $-5,23$ & 3,27 & 3,05 \\
\hline Milho & $-8,20$ & 1,65 & $-1,76$ & $-8,20$ & 2,75 & $-0,13$ \\
\hline Fruticultura & $-0,23$ & 0,53 & $-0,09$ & $-0,20$ & 0,04 & 0,47 \\
\hline Outros da agricultura & $-1,31$ & 0,95 & $-0,22$ & $-0,98$ & 0,34 & 0,76 \\
\hline Pecuária & $-0,30$ & 0,39 & $-0,03$ & $-0,29$ & 0,05 & 0,39 \\
\hline Carnes & $-0,16$ & 0,35 & $-0,10$ & $-0,11$ & 0,04 & 0,32 \\
\hline Indústria do açúcar e álcool & $-0,15$ & 0,19 & $-0,11$ & 0,02 & 0,06 & 0,14 \\
\hline Outros agroindustriais & $-0,15$ & 1,28 & $-0,14$ & $-0,03$ & 0,44 & 0,94 \\
\hline Adubos e fertilizantes & $-0,02$ & 0,91 & 0,00 & $-0,02$ & 0,00 & 0,91 \\
\hline Energia & 0,00 & $-0,01$ & 0,00 & 0,00 & $-0,01$ & 0,02 \\
\hline Madeira e mobiliário & $-0,14$ & 0,26 & $-0,08$ & $-0,14$ & 0,03 & 0,23 \\
\hline Outras indústrias & 0,00 & $-0,03$ & 0,00 & 0,00 & $-0,09$ & 0,00 \\
\hline Comércio & 0,01 & 0,03 & 0,00 & 0,01 & 0,00 & 0,03 \\
\hline Serviços & 0,01 & $-0,03$ & 0,00 & 0,01 & $-0,05$ & $-0,03$ \\
\hline
\end{tabular}

Fonte: Resultados da pesquisa.

Neste cenário, os setores da economia norte-americana com maiores reduções porcentuais na produção seriam os seguintes: Milho, Soja, Outros da agricultura e Cana-de-açúcar e beterraba. Os porcentuais de queda na produção desses setores foram de $8,20 \%, 5,73 \%, 1,31 \%$ e $0,68 \%$, respectivamente.

A redução de subsídios na agricultura norte-americana promoveria impactos diferenciados na produção setorial da economia brasileira. Os resultados apresentados para o Brasil, na Tabela 1, mostram que poderiam ocorrer ganhos em alguns setores e perdas em outros. Contudo, os setores agroindustriais expandiriam suas produções. Os setores agroindustriais com maior crescimento seriam os de Soja, Milho, Outros agroindustriais e Outros da agricultura. As taxas de crescimento da produção desses setores chegariam a 3,80\%,1,65\%, 1,28\% e 0,95\%, respectivamente. O Brasil apresentaria ainda quedas na produção das seguintes atividades: Energia, Outras indústrias e Serviços. Uma justificativa para a queda na produção desses setores está associada à combinação de estoque fixo de fatores com mobilidade setorial. Dessa maneira, choques que alteram os retornos marginais nos setores agrícolas levam à migração do capital dos setores industriais e dos serviços para a agricultura. 
Com a contração na produção agroindustrial dos EUA haveria queda nas exportações agroindustriais. Apenas setores como Adubos e fertilizantes, Energia, Outras indústrias, Comércio e Serviços conseguiriam manter as exportações nos EUA. No entanto, as mudanças positivas nas exportações desses últimos setores seriam pequenas e não suficientes para compensar a redução nas exportações agroindustriais totais. Os setores com as exportações e importações mais impactadas pela redução dos LDP, nos EUA, seriam Soja e Milho. As exportações desses setores se reduziriam em 2,82\% e 1,76\%, e as importações, em 5,23\% e 8,20\%, respectivamente. Conforme resultados apresentados na Tabela 1, pode-se inferir ainda que ocorreriam quedas nas importações dos EUA. As justificativas principais para esse fenômeno estariam na desaceleração do crescimento, além da transformação da produção de produtos destinados à exportação em produtos destinados ao mercado doméstico.

O Brasil, por sua vez, apresentaria elevação das exportações e importações agroindustriais. Os setores com as exportações mais impactadas pela redução nos LDP seriam Soja e Milho, diferenciando-se nas importações, que apresentariam impactos maiores nos setores Soja e Outros agroindustriais. Ademais, o setor Adubos e fertilizantes teria elevação nas importações, sendo esse resultado esperado, devido à expansão das atividades agrícolas e, portanto, à maior demanda por esse produto.

No entanto, as variações relativas devem ser analisadas com cautela, pois um setor pode apresentar variação porcentual elevada, mas valor absoluto pouco expressivo. Na Tabela 2, são apresentados os resultados em valores absolutos ${ }^{6}$ para produção, exportações e importações de EUA e Brasil. Esses resultados colocam em destaque o potencial de distorção dos LDP sobre a produção, as exportações e as importações agroindustriais dos EUA. Exemplo, se os LDP concedidos durante o FSRIA fossem, em média, menores em $60 \%$, a produção de Milho cairia cerca de $\mathrm{R} \$ 2,88$ bilhões ao ano ou mesmo US\$1,56 bilhão ao ano.

6 Os valores das variações absolutas apresentados no texto foram obtidos pela multiplicação dos valores das variações relativas, apresentados na Tabela 1 , pelos valores da base de dados utilizada, ou seja, a Matriz de Contabilidade Social do Brasil e dos Estados Unidos do ano de 1999. 
Tabela 2 - Variações Absolutas na Produção, nas Exportações (E) e nas Importações (M) Setoriais Devido à Redução de 60\% na Média Anual dos LDP dos EUA, no Período 2002-2007 (em Milhões de Reais)

\begin{tabular}{|c|c|c|c|c|c|c|}
\hline \multirow[t]{2}{*}{ Setores } & \multicolumn{2}{|c|}{ Produção } & \multicolumn{2}{|c|}{ EUA } & \multicolumn{2}{|c|}{ BRA } \\
\hline & EUA & BRA & $\mathrm{E}$ & $M$ & $\mathrm{E}$ & $M$ \\
\hline Cana-de-açúcar e beterraba & $-32,65$ & 12,68 & $-0,70$ & $-0,05$ & 0,04 & 0,42 \\
\hline Soja & $-1.450,07$ & 306,49 & $-49,83$ & $-50,22$ & 80,68 & 9,73 \\
\hline Milho & $-2.883,83$ & 87,04 & $-43,32$ & $-215,42$ & 0,35 & $-0,27$ \\
\hline Fruticultura & $-49,29$ & 32,02 & $-1,35$ & $-23,41$ & 0,12 & 1,14 \\
\hline Outros da agricultura & $-2.696,64$ & 427,71 & $-31,03$ & $-85,90$ & 2,96 & 13,57 \\
\hline Pecuária & $-654,50$ & 218,70 & $-4,48$ & $-57,11$ & 0,31 & 8,66 \\
\hline Carnes & $-220,21$ & 93,64 & $-7,12$ & $-5,70$ & 1,00 & 1,66 \\
\hline Indústria do açúcar e álcool & $-28,25$ & 32,28 & $-1,23$ & 0,39 & 1,63 & 0,04 \\
\hline Outros agroindustriais & $-1.789,15$ & $1.278,07$ & $-98,21$ & $-42,19$ & 54,97 & 49,26 \\
\hline Adubos e fertilizantes & $-10,89$ & 69,63 & 0,11 & $-3,51$ & 0,00 & 35,94 \\
\hline Energia & $-31,91$ & $-14,63$ & 0,13 & $-6,07$ & $-0,23$ & 2,62 \\
\hline Madeira e mobiliário & $-512,11$ & 43,25 & $-9,80$ & $-81,00$ & 0,62 & 1,24 \\
\hline Outras indústrias & 329,94 & $-128,14$ & 8,28 & 51,74 & $-40,06$ & 3,18 \\
\hline Comércio & 270,07 & 35,73 & 2,21 & $-2,28$ & $-0,24$ & 0,40 \\
\hline Serviços & $1.279,67$ & $-212,27$ & 5,02 & 24,84 & $-6,43$ & $-6,16$ \\
\hline Total do agronegócio & $-9.804,57$ & $2.488,63$ & $-237,30$ & $-479,61$ & 142,07 & 84,21 \\
\hline Total Líquido & $-8.479,80$ & $2.282,20$ & $-231,35$ & $-495,90$ & 95,73 & 121,43 \\
\hline
\end{tabular}

Fonte: Resultados da pesquisa.

Brandão e Lima (2006) aplicaram um modelo econométrico, visando medir os impactos da eliminação total dos Marketing Loan Assistance para soja nos EUA. Esses autores afirmam que a eliminação desses instrumentos, entre os quais o LDP, que é um dos mais importantes, levaria a uma diminuição da produção de soja nos EUA de 4,2 milhões de toneladas, em média, no período de 1998 a 2004. Para comparação, multiplicou-se esse montante pelo preço médio da soja nos EUA, nesse mesmo período, e constatou-se que essa queda na produção equivaleria a uma queda de cerca de US\$ 1,13 bilhão, em média, no valor da produção de soja no período de 1998 a 2004. Salienta-se que nesta pesquisa, com a redução de $60 \%$ no valor médio anual dos LDP no período de 2002 a 2007, haveria queda na produção de soja nos EUA de aproximadamente US\$783,23 milhões. As diferenças encontradas nesses resultados são comuns, uma vez que Brandão e Lima (2006) aplicaram um modelo de equilíbrio parcial, ou seja, apenas para o setor Soja, ao passo que, nesta pesquisa,

7 Segundo Brandão e Lima (2006), os recursos do Marketing Loan Assistance Program são concedidos por dois canais: os Loan Program e os Loan Deficiency Payment (LDP). Os Loan Program são empréstimos de comercialização, por meio dos quais os produtores obtêm recursos antecipadamente para comercialização, podendo utilizar a produção como forma de pagamento do empréstimo. 
aplicou-se um modelo de equilíbrio geral, considerando 15 setores e suas interligações. Ademais, há diferenças no período de análise e, portanto, no montante de subsídios considerados. Contudo, o importante é que ambos os trabalhos mostram que a redução de subsídios diminui a produção de soja nos EUA.

Dos resultados em valores absolutos, pode-se inferir ainda que a redução dos LDP promoveria diminuição de $\mathrm{R} \$ 9,80$ bilhões na produção dos setores do agronegócio nos EUA (Tabela 2). As perdas líquidas na produção da economia norte-americana seriam menores que as perdas do agronegócio, devido à expansão na produção de Outras indústrias, Comércio e Serviços, que compensaria em parte a diminuição da produção agroindustrial. As quedas líquidas de produção para a economia como um todo atingiriam $\mathrm{R} \$ 8,47$ bilhões, comprovando que os LDP foram responsáveis por fortes distorções na produção agroindustrial desse país. Portanto, pode-se inferir que a produção agroindustrial dos EUA seria menor em cerca de $\mathrm{R} \$ 60$ bilhões no FSRIA.

No Brasil, a redução desses subsídios elevaria a produção em todos os setores agroindustriais. Os aumentos na produção do agronegócio atingiram $\mathrm{R} \$ 2,48$ bilhões. As alterações gerais na produção da economia brasileira seriam também menores que aquelas na produção agroindustrial, isto é, há ligeira contração da produção dos setores relacionados a manufaturados, energia e serviços. Nessa conjuntura, haveria aumento na produção total de $\mathrm{R} \$ 2,28$ bilhões. A variação absoluta da produção do agronegócio no Brasil, no período 2002-2007, alcançaria cerca de R 15 bilhões.

Esses resultados tornam-se ainda mais significativos quando se considera que esses setores são fundamentais na geração de renda e de emprego na economia brasileira. Guilhoto et al. (2006) destacam que grande parte do valor da produção desses setores - principalmente de Outros da agricultura e Pecuária - é oriunda da agricultura familiar. Segundo esses autores, o segmento da agropecuária familiar brasileira e as cadeias produtivas a ela interligadas responderam por $10,1 \%$ do PIB brasileiro em 2003.

As variações absolutas nas exportações e importações setoriais e totais dos EUA e do Brasil mostram que a redução dos LDP concedidos à agricultura norte-americana levaria à diminuição das exportações e importações agroindustriais dos EUA em R \$ 237,29 milhões e R \$479,61 milhões, respectivamente, conforme Tabela 2.

Brandão e Lima (2006) calcularam também as variações nas exportações de soja dos EUA e do Brasil devido à redução dos Marketing Loan Assistance nos EUA. De acordo com esses autores, a eliminação total desses subsídios, no período de 1998 a 2004, geraria redução média de US\$177,42 milhões nas exportações de 
soja norte-americanas e elevariam as exportações de soja brasileira em uma média de US\$239,14 milhões. Nesta pesquisa, a mudança nas exportações de soja dos EUA, com corte simulado de 60\% nos LDP, foi de US\$26,92 milhões. Quanto aos resultados encontrados para o Brasil, haveria variações de US $\$ 43,58$ milhões. Salienta-se que os valores encontrados por Brandão e Lima (2006) e nesta pesquisa apontam para uma mesma direção: os subsídios agrícolas dos EUA distorcem os fluxos comerciais, devendo haver maiores pressões nos fóruns da OMC para que ocorra a sua redução.

O agronegócio brasileiro apresentaria reação positiva à redução dos LDP na agricultura norte-americana. Haveria aumento nas exportações e importações dos setores agroindustriais. As exportações desses setores cresceriam em R \$ 142,06 milhões e as importações em $\mathrm{R} \$ 84,20$ milhões, gerando um saldo positivo para a balança comercial do agronegócio de $\mathrm{R} \$ 57,86$ milhões por ano.

\section{Conclusões}

Constatou-se que a redução dos LDP nos EUA resultaria em impactos significativos sobre a produção e sobre os fluxos comerciais dos EUA. Os setores Milho, Outros da agricultura, Outros agroindustriais e Soja teriam a produção mais impactada por esse instrumento. Quanto às distorções nos fluxos de comércio externo, destaca-se que os setores com as exportações mais impactadas foram Outros agroindustriais, Soja, Milho e Outros da agricultura.

Destaca-se que a maior parte dos subsídios LDP considerados em Outros da agricultura é oriunda de subvenções concedidas aos produtores de algodão. Dessa maneira, pode-se concluir que, além dos setores Soja e Milho, as subvenções concedidas aos produtores de algodão nos EUA certamente geram distorções superiores aos limites permitidos pela cláusula de minimis, que atualmente permite o uso de recursos para subsidiar a produção agrícola nos EUA, desde que as distorções não ultrapassem $5 \%$ do valor da produção do produto específico.

A redução dos subsídios agrícolas dos EUA promoveria maior competitividade das exportações brasileiras, porque propiciaria aumentos de produção e produtividade, reduzindo os custos relativos do Capital e do Trabalho na agricultura brasileira, criando assim oportunidades para o crescimento do agronegócio brasileiro. Em especial, maiores impactos ocorreriam na produção setorial de Outros agroindustriais, Outros da agricultura, Soja e Pecuária. Quanto aos fluxos comerciais da economia brasileira, ocorreria aumento das exportações, porque a queda da produção e das 
exportações agroindustriais dos EUA geraria a possibilidade de maior produção e exportações agroindustriais brasileiras.

Tendo em vista o exposto, pode-se concluir que as negociações multilaterais com a Organização Mundial de Comércio são necessárias para que cada país possa garantir uma fatia dos ganhos advindos da liberalização do comércio. Para os países em desenvolvimento, especialmente o Brasil, ganhos expressivos são mais prováveis se houver contrapartidas dos países desenvolvidos em propiciar maior acesso aos mercados agroindustriais, em que as economias emergentes são mais competitivas.

Entre as limitações da metodologia aplicada nesta pesquisa, cita-se a não desagregação de setores como arroz e algodão, que recebem volumes consideráveis de subsídios nos EUA. Deve-se também mencionar o caráter estático do modelo de equilíbrio geral, que não permite verificar o comportamento das variáveis econômicas no tempo, além de não permitir incorporar os efeitos das expectativas nas decisões de investimentos. No entanto, os resultados desta pesquisa contribuem, sobremaneira, para o entendimento dos principais impactos dos subsídios agrícolas dos EUA na própria economia norte-americana, bem como sobre a economia brasileira. Ademais, fica como sugestão para pesquisas futuras a desagregação de setores cuja importância é destacada para o Brasil, como, por exemplo, do setor algodoeiro.

\section{Referências}

BANCO DA AMAZÔNIA S/A - BASA. Matrizes insumo-produto Amazônia, região Norte e seus Estados. Belém, PA: BASA, 2004. 1 CD-ROM.

BEA - BUREAU ECONOMIC ANALYSIS. Annual industry accounts. BEA, 2005. Disponível em: <http://www.bea.gov/>. Acesso em: 10 jan. 2006.

BERALDO, A. D. U.S. Farm Security aumenta subsídios à produção. Revista Gleba, Brasília, v. 47, n. 184, p. 8-9, maio./jun. 2002.

BLS - BUREAU OF LABOR STATISTICS. Unemployment rates. BLS, 2007. Disponível em: <http://www.bls.gov/>. Acesso em: 10 jan. 2007.

BRAGA, M. J. Reforma fiscal e desenvolvimento das cadeias agroindustriais. 1999. 155 f. Tese (Doutorado em Economia Rural) - Universidade Federal de Viçosa, 1999.

BRANDÃO, A. S. P.; LIMA, E. C. R. Impacts of the U.S. subsidy to soybeans on world prices, production and exports. Revista de Economia e Sociologia Rural, Brasília, v. 44, n. 4, p. 631-676, out./dez. 2006.

BURNQUIST, H. L.; MIRANDA, S. H. G. Desempenho recente das exportações brasileiras de açúcar: uma abordagem de "market share" constante. Revista de Economia e Sociologia Rural, Brasília, v. 37, n. 3, p. 69-90, jul./set. 1999. 
CARVALHO, F. M. A. O comportamento das exportações brasileiras e a dinâmica do complexo agroindustrial. 1995. 126 f. Tese (Doutorado em Economia Agrária) - Escola Superior de Agricultura Luiz de Queiroz, 1995.

CASTILHO, M. R. Algumas considerações sobre o uso de modelos computáveis de equilíbrio geral como instrumento de análise do setor externo brasileiro. Rio de Janeiro: Fundação Centro de Estudos de Comércio Exterior/IPEA, 1994. 26 p. (Textos para Discussão, n. 97).

DERVIS, K.; MELO, J.; ROBINSON, S. General equilibrium models for development policy. Cambridge: Cambridge University, 1984. 526 p. (World Bank Research Publication).

FED - FEDERAL RESERVE BANK. Flow of founds accounts of the United States. Washington, DC: Board of Governors of the Federal Reserve System, dez. 2005. $104 \mathrm{p}$.

FEIJÓ, C. A.; RAMOS, R. L. O.; YOUNG, C. E. F.; LIMA, F. C. F. C.; GALVÃO, O. J. A. Contabilidade social: o novo sistema de contas nacionais do Brasil. 2 ed. Rio de Janeiro: Elsevier, 2003. 413 p.

FERREIRA FILHO, J. B. S. Introdução aos modelos aplicados de equilíbrio geral: conceitos, teorias e aplicações. Piracicaba; SP: ESALQ, 1998. 41 p. (Série Didática, n. 120).

FIGUEIREDO, A.M. Diferenciação por origem na competitividade das exportações mundiais da agroindústria de soja, no período de 1990 a 2002. 2004. $133 \mathrm{f}$. Dissertação (Mestrado em Economia Aplicada) - Universidade Federal de Viçosa, 2004.

FOSSATI, A. Economic modeling under the applied general equilibrium approach. Brookfiel: Avebury, 1996. 293 p.

GUILHOTO, J. J. M.; SESSO FILHO, U. A. Estrutura produtiva da Amazônia: uma análise de insumo-produto. Belém: Banco da Amazônia, 2005. 320 p.

GUILHOTO, J. J. M.; SILVEIRA, F. G.; ICHIARA, S. M.; AZZONI, C. R. A importância do agronegócio familiar no Brasil. Revista de Economia e Sociologia Rural, Brasília, v. 44, n. 3, p. 355-383, jul./set. 2006.

IPEA - INSTITUTO DE PESQUISA ECONÔMICA APLICADA. Séries históricas. IPEA, 2006. Disponível em: <http://www.ipeadata.gov.br>. Acesso em: 20 abr. 2006.

JANK, M. S.; JALES, M. Q. M. A agricultura nas negociações da OMC, ALCA e EUMERCOSUL: impasses e perspectivas. São Paulo: ICONE, nov. 2003. 16 p.

LEAMER, E. E.; STERN, R.M. Quantitative international economics. Chicago: Aldine Publ., 1970. p. 171-183.

LIRIO, V. S. Do MERCOSUL à ALCA: impactos sobre o complexo agroindustrial brasileiro. 2001. 208 f. Tese (Doutorado em Economia Rural) - Universidade Federal de Viçosa, 2001. 
NAJBERG, S.; RIGOLON, F. J. Z.; VIEIRA, S. P. Modelo de equilíbrio geral computável como instrumento de política econômica: uma análise de câmbio x tarifas. Rio de Janeiro: BNDES, 1995. (Texto para Discussão n. 30).

OLIVEIRA, M. A. S. Aumento da oferta e redução de impostos nos serviços de infraestrutura na economia brasileira: uma abordagem de equilíbrio geral. 2006. 153 f. Tese (Doutorado em Economia Aplicada) - Universidade Federal de Viçosa, 2006.

OMC - ORGANIZAÇÃO MUNDIAL DO COMÉRCIO. Doha work programme: preparations for the sixth session of the ministerial conference draft ministerial text. OMC, 2005. Disponível em: <http://www.wto.org/english/thewto_e/ minist_e/min05_e/ draft_min05_text_e.pdf>. Acesso em: 13 nov. 2006.

ORDEN, D. Reform's stunted crop: congress re-embraces agriculture subsidies. Regulation: The Cato Review of Business and Government, v. 25, n. 1, p. 2632, 2002.

PONCIANO, N. J. Ajustamento na política comercial brasileira e seus efeitos nas cadeias agroindustriais. 2000. 161 f. Tese (Doutorado em Economia Rural) Universidade Federal de Viçosa, 2000.

RAMOS, R. L. O. Mudanças estruturais reais nas matrizes de insumo-produto: Brasil - 1980/1985. Pesquisa e Planejamento Econômico, v. 26, n. 1, p. 93-117, abr. 1996.

SCHUH, G. E. Comércio internacional de produtos agrícolas ALCA e OMC. Revista de Política Agrícola, ano 13, n. 2, p. 17-25, abr./jun. 2004.

STALDER, S. H. G. M. Análise da participação do Brasil no mercado internacional de açúcar. 1997. 121 f. Dissertação (Mestrado em Economia Aplicada) - Escola Superior de Agricultura Luiz de Queiroz, 1997.

SHOVEN, J. B.; WHALLEY, J. Applying general equilibrium. 3. ed. Cambridge: Cambridge University Press, 1998. 299 p.

USDA/ERS - UNITED STATES DEPARTMENT OF AGRICULTURE/ ECONOMIC RESEARCH SERVICE. WTO agricultural trade policy commitments database. USDA, 2006. Disponível em: < http://www.ers.usda. gov/db/Wto/>. Acesso em: 20 fev. 2006.

VIEIRA, W. C. Modelos aplicados de equilíbrio geral: formulação e análise utilizandose o MPSGE. Economia Rural, Viçosa, v. 8, n. 4, p. 22-27, 1997. 


\section{Apêndice A - Resumo do Modelo Analítico}

As principais relações econômicas dos agentes são representadas por um conjunto de equações não lineares, que foi montado baseando-se em Dervis et al. (1984), Najberg et al. (1995), Fossati (1996), Shoven e Whaley (1998), Braga (1999), Ponciano (2000) e Lirio (2001). As equações do modelo foram subdivididas em dez subconjuntos, representando os principais agregados macroeconômicos para uma economia aberta. Para simplificar a identificação e leitura das variáveis, suas apresentações foram feitas da seguinte forma: variáveis em letra maiúscula são endógenas; em letra minúscula, exógenas, e em letras gregas, parâmetros. As equações efetivamente computadas pelo modelo matemático são apresentadas nos itens A.l. a A.11.

\section{A.1 Utilidade dos Agentes}

Função de preferências: $U=\psi_{i}\left[\delta_{i} D_{i}^{-\varphi_{i}^{S}}+\delta_{1} M_{i}^{-\varphi_{i}^{S}}\right]^{-1 / \varphi_{i}^{s}} \quad i=1,2, \ldots, 15$

\section{A.2 Estruturas Produtivas e Demanda dos Fatores}

Consumo intermediário: $C I_{i}=\sum_{j} \alpha_{i j} X_{j} \quad i, j=1,2, \ldots, 15$

Valor adicionado: $V A_{i}=\phi_{i}\left[\delta_{i} L^{-\rho_{i}^{s}}+\delta_{1} K^{-\rho_{i}^{s}}\right]^{-1 / \rho_{i}^{s}} \quad i=1,2, \ldots, 15$

Demanda de trabalho: $D F_{i}^{L}=\phi_{i}^{-1}\left[\left(1-\delta_{i}\right)\left(\frac{\delta_{i} P_{K}}{\left(1-\delta_{i}\right) P_{L}}\right)^{\rho_{i}^{s} / 1+\rho_{i}^{s}}+\delta_{i}\right]^{1 / \rho_{i}^{s}} i=1,2, \ldots, 15$ 
Demanda de capital: $D F_{i}^{K}=\phi_{i}^{-1}\left[\delta_{i}\left(\frac{\delta_{1} P_{L}}{\delta_{i} P_{K}}\right)^{\rho_{i}^{S} / 1+\rho_{i}^{S}}+\left(1-\delta_{i}\right)\right]^{1 / \rho_{i}^{S}} i=1,2, \ldots, 15$

\section{A.3 Produção e Demandas Domésticas e Externas}

Produção doméstica: $X_{i}=\beta_{i}\left[\gamma_{i} V D_{i}^{\rho_{i}^{T}}+\gamma_{1} E_{i}^{\rho_{i}^{T}}\right] \frac{1 / \rho_{i}^{T}}{i=1,2, \ldots, 15}$

Oferta de exportação: $E_{i}=V D_{i}\left[\frac{\left(1-\gamma_{i}\right) P_{i}^{E}}{\gamma_{i} P_{i}^{D}}\right]^{1 / \rho_{i}^{T}-1} \quad i=1,2, \ldots, 15$

Vendas domésticas: $V D_{i}=E_{i}\left[\frac{\gamma_{i} P_{i}^{D}}{\left(1-\gamma_{i}\right) P_{i}^{E}}\right]^{1 / \rho_{i}^{T}-1} \quad i=1,2, \ldots, 15$

Oferta de bens e serviços: $Q_{i}=\phi_{i}\left[\delta_{i} D_{i}^{-\omega_{i}^{S}}+\left(1-\delta_{i}\right) M_{i}^{-\omega_{i}^{S}}\right]^{-1 / \omega_{i}^{s}} \quad i=1,2, \ldots, 15$

Demanda de exportação: $E_{i}=E_{i}^{o}\left(P^{E}\right)^{v}\left(\frac{\sum_{i=1}^{n}\left(P^{E}\right)^{1+v} E_{i}^{o}}{\sum_{i=1}^{n}\left(P^{M}\right)^{1+\mu} M_{i}^{o}}\right)^{\frac{v}{\mu-v}} i=1,2, \ldots, 15$

Demanda por bens domésticos: $D_{i}=M_{i}\left[\frac{\delta_{i} P_{i}^{M}}{\left(1-\delta_{i}\right) P_{i}^{D}}\right]^{1 / 1+\varphi_{i}^{S}} \quad i=1,2, \ldots, 15$

Demanda por bens importados: $M_{i}=D_{i}\left[\frac{\left(1-\delta_{i}\right) P_{i}^{D}}{\delta_{i} P_{i}^{M}}\right]^{1 / 1+\varphi_{i}^{S}} \quad i=1,2, \ldots, 15$ 


\section{A.4 Equações de Renda}

Renda interna dos fatores: $R N^{f}=\sum_{i} P F_{i}^{f} \cdot D F_{i}^{f} \quad i=1,2, \ldots, 15$

Renda total das famílias: $R N_{h}=\sum_{i} R N^{f}+\sum T G F \quad i=1,2, \ldots, 15$

Receita do governo: $R G=I D+I I+R T+I E$

Impostos diretos: $I D=R N_{h} \cdot t_{h}$

Impostos indiretos: $I I=\sum_{i} P_{i}^{X} \cdot X_{i} \cdot\left(t_{i}^{X}-s_{i}^{X}\right) \quad i=1,2, \ldots, 15$

Receitas de tarifas: $R T=\sum_{i} p w_{i}^{M} \cdot M_{i} \cdot t_{i}^{M} \cdot C N \quad i=1,2, \ldots, 15$

Impostos de exportação: $I E=\sum_{i} p w_{i}^{E} \cdot E_{i} \cdot\left(t_{i}^{E}-s_{i}^{E}\right) \cdot C N \quad i=1,2, \ldots, 15$

\section{A.5 Equações de Poupança e Investimento}

Poupança privada: $S p=R N_{h} \cdot\left(1-t_{h}\right) \cdot \tau_{h}$

Poupança do governo: $S g=R G-\left(\sum_{i} P_{i}^{Q} \cdot C G_{i}\right) \quad i=1,2, \ldots, 15$

Poupança nacional: $S N=S p+S g+s_{e} \cdot C N$

Investimento: $S N=I$

\section{A.6 Equações de Dispêndio}

Consumo privado: $C p=R N_{h} \cdot\left(1-t_{h}\right) \cdot \eta_{h}$ 
Consumo do governo: $C G_{i}=D T G+T G F \quad i=1,2, \ldots, 15$

\section{A.7 Equações de Preços}

Preços domésticos de importações: $P_{i}^{M}=p w_{i}^{M} \cdot\left(1+t_{i}^{M}\right) \cdot C N \quad i=1,2, \ldots, 15$

Preços domésticos de exportações: $P_{i}^{E}=p w_{i}^{E} \cdot\left(1-t_{i}^{E}\right) \cdot C N \quad i=1,2, \ldots, 15$

Preços dos bens e serviços: $P_{i}^{Q} Q_{i}=P_{i}^{D} D_{i}+P_{i}^{M} M_{i} \quad i=1,2, \ldots, 15$

Preços de mercadorias domésticas: $P_{i}^{X} X_{i}=P_{i}^{D} V D_{i}+P_{i}^{E} E_{i} \quad i=1,2, \ldots, 15$

\section{A.8 Condições de Equilíbrio e Fechamento do Modelo}

Função de lucro: $\Pi_{i j}(p)=R_{j}(p)-C_{i}(p) \leq 0 \quad \forall \quad i, j=1,2, \ldots, 15$

Oferta e demanda de bens e serviços: $Q_{i}=C I_{i}+C p_{i}+C G_{i}+V E S T_{i} i=1,2, \ldots, 15$

Demanda e dotação de fatores: $\sum_{i} D F_{i}^{f}=f_{s}^{f} \quad i=1,2, \ldots, 15$

Balanço de pagamentos: $p w_{i}^{E} E_{i}+s_{e}=p w_{i}^{M} M_{i}+y_{e} \quad i=1,2, \ldots, 15$

Poupança e investimentos: $S N=I$

\section{A.9 Numerário do Modelo}

Índice de preços ao consumidor: $I P C=\sum_{i} \Omega_{i} P_{i}^{X} \quad i=1,2, \ldots, 15$ 


\section{A.10 Medidas de Bem-Estar}

Variação equivalente: $V E=\frac{\left(U^{A}-U^{I}\right)}{U^{I}} \cdot R N_{h}^{I}$

\section{A.11 Número de Equações Estimadas e Definição das Variáveis}

Considerando os dez blocos de equações apresentados, verifica-se que, representando cada grupo entre parênteses, o modelo possui $(1)+(4 n)+(7 n)+(7)+(4)+(2)$ $+(4 n)+(4 n+1)+(1)+(1)$ equações, totalizando $19 n+18$ equações. Nesta pesquisa, o número de setores é $n=15$, tendo, portanto, o modelo utilizado um número total de 302 equações para cada país. O software utilizado na solução das equações foi o Mathematical Programming System for General Equilibrium (MPSGE). Segundo Vieira (1997), o uso desse programa dispensa a linearização das equações, pois ele é adaptado para obter soluções de sistemas de equações não lineares.

Variáveis endógenas: $U=$ utilidade dos agentes; $\Pi_{i}=$ lucro; $R_{j}=$ receita unitária; $C_{i}=$ custo unitário de produção; $X_{i}=$ produção doméstica; $V D_{i}=$ vendas domésticas; $D_{i}=$ demanda por bens domésticos; $M_{i}=$ importações; $E_{i}=$ exportações; $Q_{i}=$ oferta de bens e serviços; $C I_{i}=$ consumo intermediário; $C G_{i}=$ consumo do governo; $D F_{i}^{L}=$ demanda por trabalho; $D F_{i}^{K}=$ demanda por capital; $D F_{i}^{f}=$ demanda por fatores; $V E S T_{i}=$ variação de estoques; $I=$ investimento; $S N=$ poupança nacional; $S_{p}=$ poupança privada; $S_{g}=$ poupança do governo; $I P C=$ numerário; $I D=$ impostos diretos; $I I=$ impostos indiretos; $I E=$ impostos sobre exportações; $R T=$ receita com tarifas de importação; $C N=$ taxa de câmbio nominal; $P_{i}^{D}=$ preços das vendas domésticas; $P_{i}^{E}=$ preço doméstico das exportações; $P_{i}^{M}=$ preço doméstico das importações; $P_{i}^{Q}=$ preço doméstico dos bens compostos; $P_{i}^{X}=$ preço da produção doméstica; $P F_{i}^{f}=$ preço médio dos fatores; $R N^{f}=$ renda dos fatores; $R N_{h}=$ renda total dos consumidores; $R G=$ receita do governo; $V A_{i}=$ valor adicionado de cada setor; $C p_{i}=$ consumo privado total; $T G F=$ transferência do governo para as famílias, e $D T G=$ dispêndios totais do governo.

Variáveis exógenas: $p w_{i}^{M}=$ preço internacional das importações; $p w_{i}^{E}=$ preço internacional das exportações; $t_{i}^{M}=$ alíquota das tarifas sobre as importações; $t_{i}^{E}=$ alíquota das tarifas sobre as exportações; $s_{i}^{E}=$ subsídios às exportações; $t_{h}=$ alíquota do imposto direto incidente sobre a renda das famílias; $t_{i}^{X}=$ alíquota do 
imposto indireto incidente sobre a produção doméstica; $s_{i}^{X}=$ subsídios à produção; $s_{e}=$ poupança externa; $f s^{f}=$ oferta de fatores (dotação), e $y_{e}=$ renda líquida enviada ao exterior.

Parâmetros: $\psi_{i}=$ parâmetro da função utilidade; $\alpha_{i j}=$ coeficientes técnicos calculados para a matriz de insumo-produto ou parâmetro de produtividade; $\beta_{i}=$ parâmetro de tecnologia das funções CET; $\phi_{i}=$ parâmetro tecnológico das funções CES; $\delta_{i}=$ parâmetro de distribuição da função CES; $\gamma_{i}=$ parâmetro de distribuição da função CET; $\varphi_{i}^{S}=\omega_{i}^{S}=$ parâmetro de substituição no consumo de bens e serviços; $\rho_{i}^{S}=$ parâmetro de substituição de fatores; $\rho_{i}^{T}=$ parâmetro de transformação; $\sigma_{i}^{S}=1 / 1+\rho_{i}^{S}=$ elasticidade de substituição de fatores; $\sigma_{i}^{T}=1 / \rho_{i}^{T}-1=$ elasticidade de transformação da função CET; $\sigma_{i}^{S C}=1 / 1+\phi_{i}^{S}=$ elasticidade de substituição no consumo de bens e serviços domésticos e importados; $\eta_{h}=$ propensão marginal a consumir das famílias; $\tau_{h}=$ propensão marginal a poupar das famílias, e $\Omega_{i}=$ parâmetro do índice de preço.

Os parâmetros utilizados para obtenção das soluções de um MAEG são comumente obtidos por meio da calibração e estimados econometricamente e, ou, por outros métodos. Entretanto, a maioria dos parâmetros é obtida por meio da calibração, ${ }^{8}$ que consiste em encontrar os parâmetros necessários para geração das soluções do MAEG, de maneira que os dados referentes a um ano-base das variáveis endógenas sejam uma solução de equilíbrio para a economia, ou benchmark equilibrium. Os parâmetros são calculados utilizando-se apenas uma única observação das variáveis exógenas em um ano-base e, ou, quando não puderem ser calculados, deverão ser obtidos na literatura econômica, em outras pesquisas ou, em último caso, arbitrariamente (FERREIRA FILHO, 1998).

8 Discussão mais detalhada sobre a calibração de modelos de equilíbrio geral pode ser obtida em Fossati (1996), Ferreira Filho (1998) e Oliveira (2006). 